\title{
N-Cadherin Prodomain Processing Regulates Synaptogenesis
}

\author{
Analía Reinés, Louis-Philippe Bernier, Robyn McAdam, Wiam Belkaid, Weisong Shan, Alexander W. Koch, \\ Philippe Séguéla, David R. Colman, ${ }^{\dagger}$ and Ajit S. Dhaunchak \\ The Montreal Neurological Institute and Hospital, McGill University, Montreal, Quebec H3A 2B4, Canada
}

Classical cadherins, which are adhesion molecules functioning at the CNS synapse, are synthesized as adhesively inactive precursor proteins in the endoplasmic reticulum (ER). Signal sequence and prodomain cleavage in the ER and Golgi apparatus, respectively, activates their adhesive properties. Here, we provide the first evidence for sorting of nonadhesive precursor N-cadherin (ProN) to the neuronal surface, where it coexists with adhesively competent mature $\mathrm{N}$-cadherin $(\mathrm{N}-\mathrm{cad})$, generating a spectrum of adhesive strengths. In cultured hippocampal neurons, a high ProN/N-cad ratio downregulates synapse formation. Neurons expressing genetically engineered uncleavable ProN make markedly fewer synapses. The synapse number can be rescued to normality by depleting surface ProN levels through prodomain cleavage by an exogenous protease. Finally, prodomain processing is developmentally regulated in the rat hippocampus. We conclude that it is the ProN/N-cad ratio and not mature N-cad alone that is critical for regulation of adhesion during synaptogenesis.

\section{Introduction}

A variety of putative adhesion molecules are localized to the CNS synapse and some regulate synapse formation (Klein, 2001; Scheiffele, 2003; Sakisaka and Takai, 2005; Shapiro et al., 2007; Siddiqui and Craig, 2011). Classical cadherins, bona fide adhesion molecules in virtually all tissue of epithelial origin, including CNS, are prominent participants in synapse formation (Takeichi, 2007; Arikkath and Reichardt, 2008). N-cadherin (N-cad) is a classical cadherin found at CNS synapses that is localized to the active zone of young neurons and the periphery of the active zone in highly mature synapses (Fannon and Colman, 1996; Uchida et al., 1996). In addition to its adhesive role during development, $\mathrm{N}$-cad plays a role in spine morphology, synaptic remodeling, plasticity, and long-term potentiation (Bozdagi et al., 2000, 2010; Togashi et al., 2002; Okamura et al., 2004; Jüngling et al., 2006; Tai et al., 2007; Mendez et al., 2010). Furthermore, synaptic stimulation modifies $\mathrm{N}$-cad conformation and distribution along the

Received Feb. 25, 2012; accepted March 14, 2012.

Author contributions: A.R., D.R.C., and A.S.D. designed research; A.R., L.-P.B., R.M., W.B., and W.S. performed research; A.W.K. contributed unpublished reagents/analytic tools; A.R., L.-P.B., R.M., W.S., P.S., D.R.C., and A.S.D. analyzed data; A.R. and A.S.D. wrote the paper.

This work was supported by grants from Canadian Institutes of Health Research, Rio Tinto Alcan, The Molson Foundation, Consejo Nacional de Investigaciones Científicas y Técnicas, and Universidad de Buenos Aires. A.S.D. is supported by an MS Society of Canada postdoctoral fellowship. We thank Dr. Madeline Pool for editing this manuscript prior to submission and Dr. Wayne Sossin for inputs on FM4-64 experiments.

†Deceased, June 1, 2011.

Correspondence should be addressed to either of the following: Dr. Ajit S. Dhaunchak, The Montreal Neurological Institute and Hospital, 3801 University Street, Montreal, Quebec H3A 2B4, Canada, E-mail: ajit.dhaunchak@mcgill.ca, or Dr. Analia Reinés, Instituto de Investigaciones Farmacológicas (Universidad de Buenos Aires-Consejo Nacional de Investigaciones Científicas y Técnicas), Junín 9565 to piso, Buenos Aires, Argentina, E-mail: areines@ffyb.uba.ar.

W. Shan's present address: Children's Hospital of Wisconsin, Medical College of Wisconsin, Milwaukee, WI 53226. A. W. Koch's present address: Protein Chemistry, Genentech, Inc., San Francisco, CA 94080.

DOI:10.1523/JNEUROSCI.0916-12.2012

Copyright $\odot 2012$ the authors $\quad 0270-6474 / 12 / 326323-12 \$ 15.00 / 0$ surface, demonstrating that synaptic adhesion is dynamically and locally controlled and modulated by synaptic activity (Tanaka et al., 2000).

Like all classical cadherins, $\mathrm{N}$-cad is synthesized on the rough endoplasmic reticulum as a precursor protein. The $\mathrm{N}$-terminal signal sequence cleavage generates a new $\mathrm{N}$ terminus and the ensuing 107 aa comprise the "prodomain" of N-cad. The prodomain renders the molecule adhesively inactive until it is removed by furin and other convertases (Ozawa and Kemler, 1990; Posthaus et al., 1998). The prodomain lacks the sites for calcium coordination, thus permitting a freely moveable nonrigid secondary structure devoid of adhesive properties (Koch et al., 2004). Transgenic expression of precursor N-cadherin (ProN), in vivo, inhibits synapse formation (Latefi et al., 2009). It is generally accepted that endogenous ProN is not found on any normal cell surface under physiological conditions. However, we recently reported that, in melanoma, not only $\mathrm{N}$-cad but also ProN can reach the cell surface where it remains uncleaved and therefore nonadhesive (Maret et al., 2010). The aberrant expression of ProN on the melanoma cell plasma membrane dramatically affects cell adhesion properties, making some tumors very invasive (Maret et al., 2010). Since melanoma is a neural crest derivative, we analyzed whether ProN can also regulate neuronal adhesion during neuronal cell development.

We show that, in cultured neurons and rodent hippocampus, the ProN expression, distribution, and processing are developmentally regulated, modulating adhesion during synaptogenesis. Unexpectedly, ProN is abundantly expressed on the surface of cultured neurons. During process outgrowth, the ProN/N-cad ratio is high $(>2)$, and, as synapse formation progresses, the ratio drops significantly $(<0.8)$, reflecting a switch from a nonadhesive state to generation of an adhesive bond between presynaptic and postsynaptic membranes. By overexpressing a mutant that is un- 
cleavable by endogenous enzymes, we show that ProN inhibits synapse formation, suggesting that ProN could act as a downregulator of synapse formation. We propose that the dynamic ProN/N-cad ratio on the neuronal surface is a previously unrecognized but important mechanism by which neurons regulate adhesion during synapse formation in the CNS.

\section{Materials and Methods}

Primary culture and transfections. Hippocampal neuronal cultures were prepared from embryonic day 18 Sprague Dawley rats as described in our previous report (Lucido et al., 2009). Briefly, hippocampal neurons were dissociated by treatment with $0.25 \%$ trypsin followed by trituration through a Pasteur pipette. Cells were plated at a density of $1 \times 10^{5} / \mathrm{cm}^{2}$ or $7 \times 10^{3} / \mathrm{cm}^{2}$ on poly-D-lysine-coated plastic dishes or glass coverslips, respectively, and maintained for up to $18 \mathrm{~d}$ in Neurobasal medium (Invitrogen) supplemented with 2\% B27 (Invitrogen) and $0.5 \mathrm{~mm}$ glutamine. Neurons were transfected by electroporation (Amaxa Biosystems) according to the manufacturer's protocol. Briefly, $4 \times 10^{6}$ hippocampal neurons were transfected in suspension with $3 \mu \mathrm{g}$ of DNA and were plated immediately on poly-D-lysine-coated glass coverslips at a density of $6-10 \times 10^{5}$ cells $/ \mathrm{cm}^{2}$. Neurons were maintained up to $18 \mathrm{~d}$ in Neurobasal medium (Invitrogen) supplemented with 2\% B27 and 0.5 mu glutamine. The average transfection efficiency was $\sim 60 \%$. For all transfections, epitope-tagged wild-type N-cad or ProN (Koch et al., 2004; Shan et al., 2004) driven by the chicken actin gene promoter was used. Mock-transfected cells and neurons expressing ProN that is uncleavable by endogenous enzymes were treated with $0.4 \mathrm{U} / \mathrm{ml}$ factor Xa (Sigma-Aldrich) at 11 and $13 \mathrm{~d}$ in vitro (DIV) and fixed at 14 DIV.

Cell and tissue homogenates. Homogenates were prepared from hippocampal neurons grown in culture for $3,5,7,10,12$, or 14 DIV by rinsing cells in PBS and solubilizing them in RIPA buffer $(10 \mathrm{~mm}$ Tris-Cl, pH 8.0, $150 \mathrm{~mm} \mathrm{NaCl,1} \%$ Igepal, $0.5 \%$ sodium deoxycholate, $0.1 \%$ SDS). Lysates were incubated on ice and spun down at full speed in a microcentrifuge for $20 \mathrm{~min}$. The resulting supernatant (detergent-soluble fraction) was saved for further analysis, and pellets were resuspended in $2 \%$ SDS, sonicated briefly, and centrifuged as above. Supernatants obtained in the first (detergent-soluble fraction) and second step (detergent-insoluble fraction) were analyzed by SDSPAGE followed by immunoblotting.

For brain homogenates, hippocampi and cortices from 1-, 3-, 5-, 7-, 10-, 15-, and 25-d-old pups (P1, P3, P5, P7, P10, P15, and P25, respectively) and from adult rats were dissected and homogenized at $25 \%(\mathrm{w} / \mathrm{v})$ in $150 \mathrm{~mm} \mathrm{NaCl}, 2$ mм EDTA, 1\% Triton X-100, 0.05\% SDS in $50 \mathrm{~mm}$ Tris- $\mathrm{HCl}, \mathrm{pH} 7.5$, containing a protease inhibitor mixture (Roche) and 1 mM PMSF. The pellets obtained after centrifugation at full speed in a microcentrifuge for $20 \mathrm{~min}$ were resuspended in $2 \%$ SDS, sonicated, and spun down as above. The supernatants obtained in the first (Triton $\mathrm{X}$-100-soluble fraction) and second (Triton X-100-insoluble fraction) steps were analyzed by SDS-PAGE followed by immunoblotting. For detection of the ProN domain released into the cell culture medium, hippocampal neuronal culture media were collected at 3, 6, 9, and 12 DIV, concentrated $(5 \times)$ using an Amicon Centricon $10 \mathrm{kDa}$ molecular weight cutoff columns (Millipore) and subjected to immunoblotting.

Cell surface biotinylation. Hippocampal neurons grown for 3, 5, or 7 DIV on poly-D-lysine-coated $60 \mathrm{~mm}$ plastic dishes were washed three times with ice-cold $2 \mathrm{mM} \mathrm{Mg}^{2+}$ in PBS, $\mathrm{pH} 8.0$, and incubated at $4^{\circ} \mathrm{C}$ for $30 \mathrm{~min}$ with $0.5 \mathrm{mg} / \mathrm{ml} \mathrm{EZ-link} \mathrm{Sulfo-NHS-LC-Biotin} \mathrm{(Pierce} \mathrm{Biotech-}$ nology) in cold PBS/2 $\mathrm{mm} \mathrm{Mg}^{2+}$. After washing three times with ice-cold $10 \mathrm{~mm}$ glycine in TBS/2 $\mathrm{mM} \mathrm{Ca}^{2+} / 2 \mathrm{mM} \mathrm{Mg}^{2+}$, neurons were lysed with RIPA buffer containing a protease inhibitor mixture (Roche) and $1 \mathrm{~mm}$ PMSF, and centrifuged at full speed in a microcentrifuge for $10 \mathrm{~min}$. Streptavidin-agarose beads (Pierce Biotechnology) were added to the supernatants, and the mixture was incubated overnight at $4^{\circ} \mathrm{C}$. After washing the beads three times with RIPA buffer, the bound proteins were eluted by boiling the beads in SDS sample buffer and subjected to SDSPAGE followed by immunoblotting.

Isolation of synaptosomes and separation of presynaptic and postsynaptic proteins. Synaptosomes were prepared as previously described (Phillips et al., 2001). Cortices and hippocampi from five male adult Sprague Dawley rats ( $5 \mathrm{~g}$ total wet weight) were homogenized separately in $15 \mathrm{ml}$ of $0.32 \mathrm{M}$ sucrose, $0.1 \mathrm{~mm} \mathrm{CaCl}_{2}, 1 \mathrm{~mm} \mathrm{MgCl}_{2}$, and $0.1 \mathrm{~mm} \mathrm{PMSF}$ at $4^{\circ} \mathrm{C}$ using a Teflon-glass homogenizer. The homogenate was brought to a final sucrose concentration of $1.25 \mathrm{M}$ by addition of $2 \mathrm{M}$ sucrose $(70 \mathrm{ml})$ and $0.1 \mathrm{mM} \mathrm{CaCl}_{2}(30 \mathrm{ml})$ and divided into six $25 \times 89 \mathrm{~mm}$ ultracentrifuge tubes. The homogenate was overlaid with $10 \mathrm{ml}$ of $1.0 \mathrm{M}$ sucrose, 0.1 $\mathrm{mm} \mathrm{CaCl}$, and with $5 \mathrm{ml}$ of $0.32 \mathrm{M}$ sucrose, $0.1 \mathrm{~mm} \mathrm{CaCl}_{2}$, and centrifuged at $100,000 \times g$ for $3 \mathrm{~h}$ at $4^{\circ} \mathrm{C}$. The synaptosomal fraction was collected at the $1.25 \mathrm{M} / 1.0 \mathrm{~m}$ sucrose interface. The presynaptic and postsynaptic components were separated as described previously (Phillips et al., 2001). Briefly, synaptosomes were sequentially extracted with $1 \%$ Triton X-100 at pH 6.0 followed by $\mathrm{pH}$ 8.0. Synaptosomes (prepared as described above) were diluted 1:10 with ice-cold $0.1 \mathrm{~mm} \mathrm{CaCl}_{2}$. The suspension was brought to a final concentration of $20 \mathrm{~mm}$ Tris, $\mathrm{pH} 6.0$, and $1 \%$ Triton X-100. Membranes were extracted on ice for $30 \mathrm{~min}$ and spun down at $40,000 \times g$ for $30 \mathrm{~min}$. The pellet (synaptosomal mem-

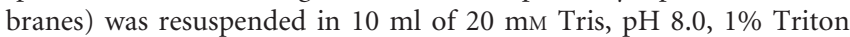
$\mathrm{X}-100$, extracted, and centrifuged as above. The supernatant contains the presynaptic components, while the final pellet comprises the postsynaptic proteins.

SDS-PAGE and immunoblot analysis. Protein concentrations from cell and brain homogenates were determined using the BCA protein assay (Pierce Biotechnology). Samples ( $10 \mu \mathrm{g}$ of protein) were dissolved in $2 \times$ SDS sample buffer, boiled, centrifuged, and run in $6,8,10$, or $4-20 \%$ precast Tris-glycine gels (Invitrogen). The proteins were then transferred to a nitrocellulose membrane, blocked with $5 \%$ milk, incubated overnight at $4^{\circ} \mathrm{C}$ with the primary antibodies, washed, and incubated with species-matched horseradish peroxidase-conjugated secondary antibodies. After stringent washings, membranes were revealed by incubating with ECL chemiluminescence substrate (PerkinElmer) and exposed with Kodak BioMax films (Sigma-Aldrich). Blots were scanned using identical parameters, and band intensity was assessed using a NIH ImageJ macro for quantifying band intensity from gels. For comparison purposes, bands were standardized against actin intensity (used as a loading control). Statistical differences were evaluated by one- or two-way ANOVA followed by Student-Newman-Keuls posttesting. Statistical significance was set at $p<0.05$.

Immunostaining. Neurons cultured for 5 or $24 \mathrm{~h}$ or 3-18 DIV were fixed for $10 \mathrm{~min}$ at room temperature (RT) in $4 \%$ paraformaldehyde/PBS solution, $\mathrm{pH}$ 7.2. After permeabilizing for $10 \mathrm{~min}$ at RT with 0.1 or $0.2 \%$ Triton X-100 and blocking for $30 \mathrm{~min}$ at RT with normal donkey serum (NDS) (Jackson ImmunoResearch), neurons were incubated overnight at $4^{\circ} \mathrm{C}$ in primary antibody diluted in $1 \%$ NDS in PBS. The following day, the cells were washed and incubated for $1 \mathrm{~h}$ at RT with appropriate secondary antibodies (Jackson ImmunoResearch or Invitrogen) and mounted using a ProLong Antifade kit (Invitrogen). For all immunocytochemical studies, control cultures were incubated with and without either primary or secondary antibodies.

The cell surface staining was performed on water-ice slurry to reduce antibody endocytosis, as described previously (Dhaunchak and Nave, 2007; Dhaunchak et al., 2011). Briefly, neurons for 3-7 DIV were washed with ice-cold Dulbecco's PBS (DPBS), incubated with ProN antibody (1:500) diluted in DPBS for 15 min, washed twice with DPBS, and fixed with $2 \%$ paraformaldehyde in DPBS. Cells were then transferred to RT, washed twice with DPBS, incubated with Cy3-conjugated secondary antibody for $30 \mathrm{~min}$, washed three times with DPBS, permeabilized with $0.1 \%$ Triton X-100 for $10 \mathrm{~min}$, blocked, and immunostained for total $\mathrm{N}$-cad as described above.

Antibodies. For immunofluorescence, the following polyclonal and monoclonal antibodies were used. Rabbit polyclonal antibodies were anti-ProN (Koch et al., 2004), anti-myc-tag (Millipore), anti- $\beta$-catenin (Sigma-Aldrich). Mouse monoclonal antibodies were anti-neuronal class III $\beta$-tubulin (clone TUJ1; Stem Cell Technologies), anti-synaptophysin (Millipore Bioscience Research Reagents), anti-PSD-95 (Affinity Bioreagents), anti-N-cadherin (clone 32; Biocompare), anti-MAP2 (Sigma-Aldrich), anti-GAD (Millipore Bioscience Research Reagents), and anti-VGLUT (Millipore Bioscience Research Reagents). F-actin was 
A
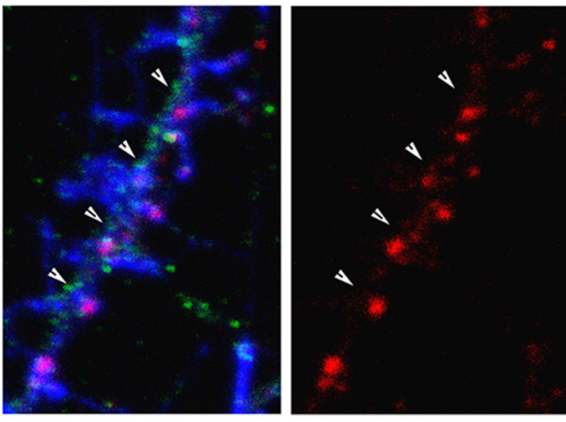

actin PSD-95 ProN

C

MAP2
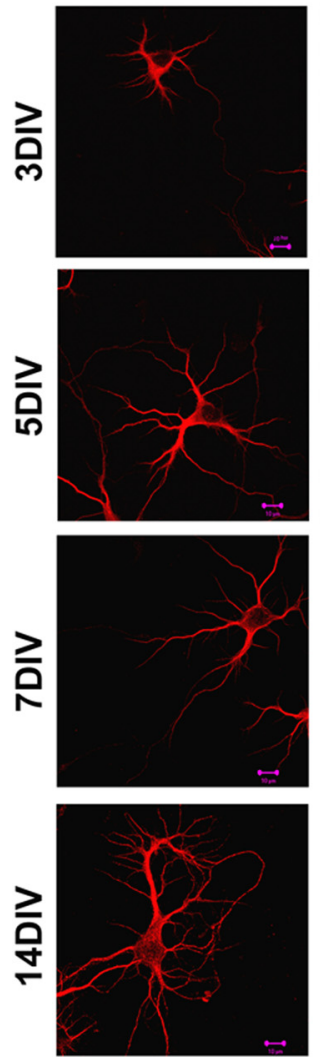

ProN
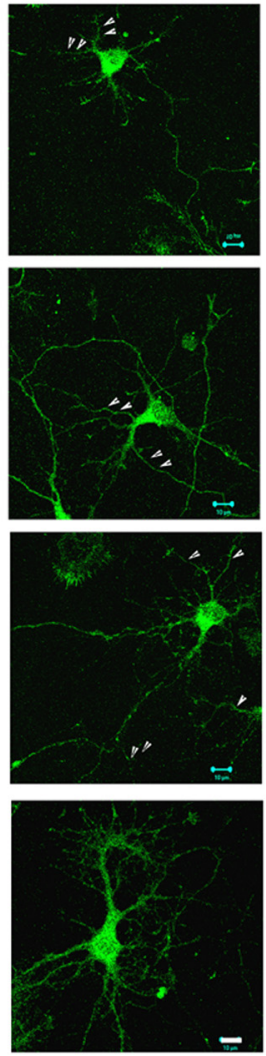

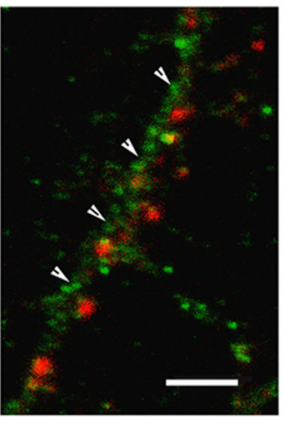

D
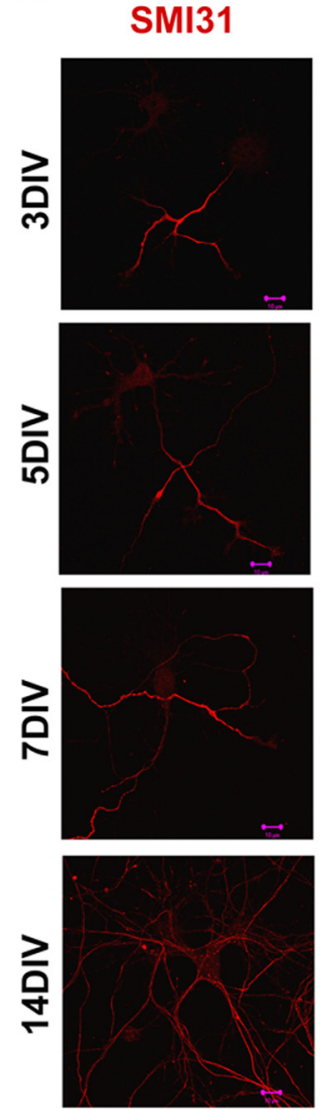

B
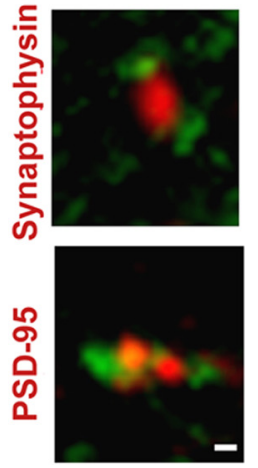

ProN

\section{ProN}
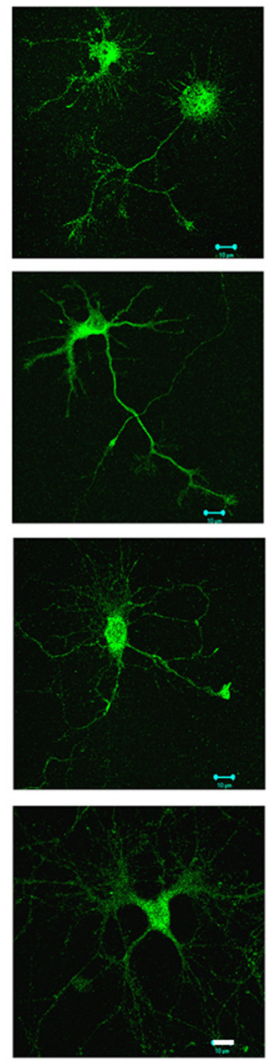

Figure 1. ProN expression during early hippocampal neuron differentiation. $A$, Primary hippocampal neurons (18 DIV) immunostained for ProN (in green), PSD-95 (in red), and actin (in blue). ProN is localized in close relationship with synapses in mature neurons. The arrowheads indicate that the small puncta of ProN immunoreactivity are in close proximity with PSD-95. B, At higher magnification, localization of ProN (green) and the presynaptic and postsynaptic puncta visualized by synaptophysin (red; top) and PSD95 (red; bottom) labeling, respectively. The close proximity of ProN with presynaptic and postsynaptic puncta can be observed in detail. C, D, Primary hippocampal neurons (3-14 DIV) immunostained for ProN (green) and the dendritic marker MAP2 (in red; C) or the axonal marker SMI31 (in red; $\boldsymbol{D}$ ). ProN is expressed in dendrites and axons throughout neuronal differentiation as shown by MAP2 and SMI31, respectively. Scale bars: $\boldsymbol{A}, 2 \mu \mathrm{m} ; \boldsymbol{B}, 0.1 \mu \mathrm{m}$; $C, D, 10 \mu \mathrm{m}$.

visualized with Alexa 488-conjugated phalloidin. Antibodies used for immunoblotting were anti-synaptophysin (clone SVP-38; SigmaAldrich), anti-PSD-95 family (clone K28/86.2; Millipore), anti-Ncadherin (MNCD2, against the EC2 domain; Developmental Studies Hybridoma Bank), anti-GluR1 (polyclonal rabbit; Millipore Bioscience Research Reagents), anti-actin (clone C4; MP Biomedicals), and antiGAPDH (monoclonal; Abcam). For immunofluorescence and immunoblot analysis, fluorochrome- and HRP-conjugated secondary antibodies were used (Jackson ImmunoResearch).

Functional labeling of presynaptic boutons. Hippocampal cultures (14 DIV) were incubated with $15 \mu \mathrm{M}$ FM4-64 (Invitrogen) in high- $\mathrm{K}^{+}$iso- osmotic HBSS (103 mM NaCl, $45 \mathrm{~mm} \mathrm{KCl,} 2 \mathrm{~mm} \mathrm{CaCl}_{2}$, and $0.5 \mathrm{~mm}$ $\mathrm{MgCl}_{2}$ ) for $90 \mathrm{~s}$ at RT followed by $15 \mathrm{~min}$ washing with dye-free medium at the same temperature to remove free FM4-64. Labeled cells were fixed with $4 \%$ paraformaldehyde for 10 min, washed with PBS three times, and imaged immediately.

FM4-64 dye unloading was obtained by two rounds of 90 s $45 \mathrm{~mm} \mathrm{KCl}$ application spaced by a $2 \mathrm{~min}$ rest interval. Three minutes after dye loading and unloading, neurons were incubated for $30 \mathrm{~s}$ with Advasep 7 (CyDex), a modified cyclodextrin, to remove excess dye. Images were acquired on an epifluorescent Zeiss Axiovert 200 microscope $(63 \times$ oil objective) after 10 min washing with HBSS after stimulation. 
A

Total N-cad
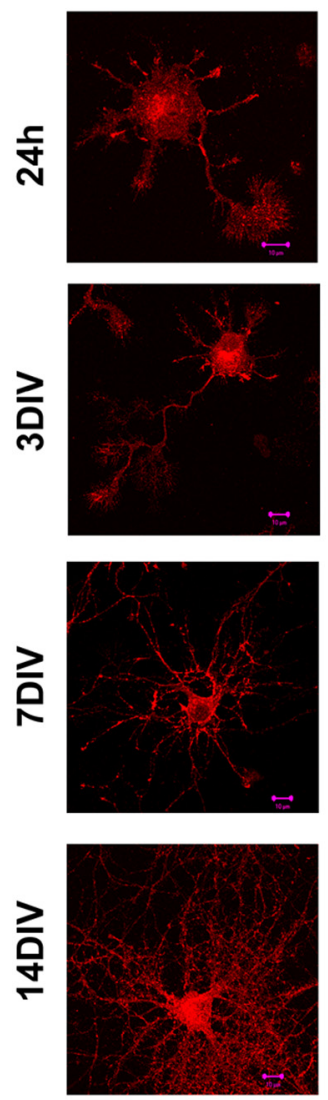

ProN
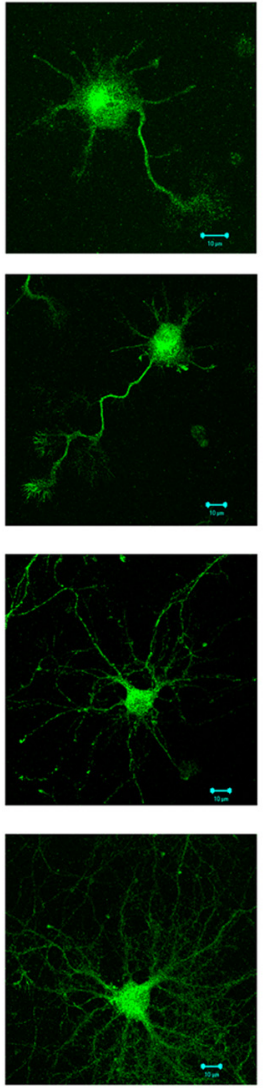

B

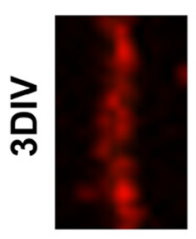

C

soluble

Hippocampal neurons (DIV)

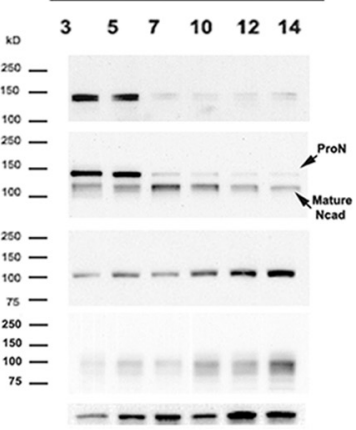

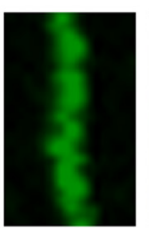

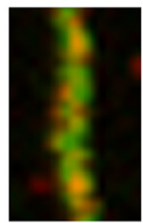

Insoluble

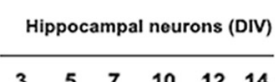

$\begin{array}{llllll}3 & 5 & 7 & 10 & 12 & 14\end{array}$

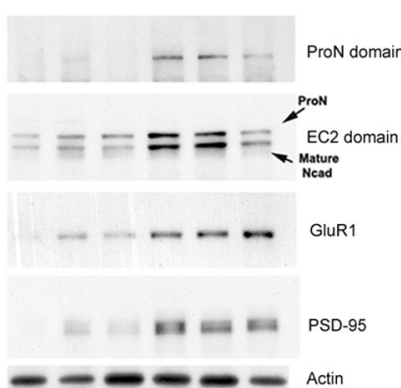

\section{Merged}
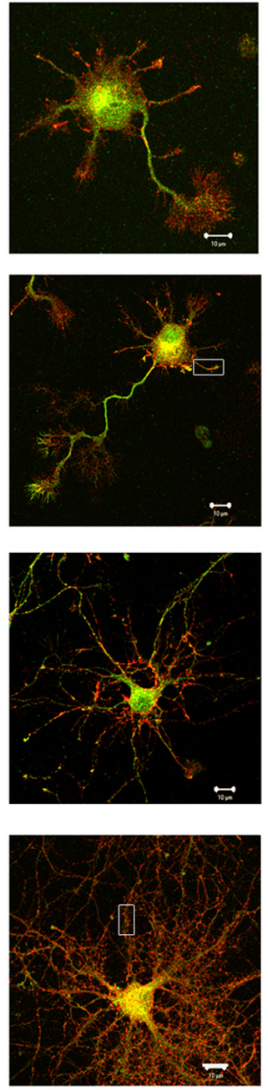
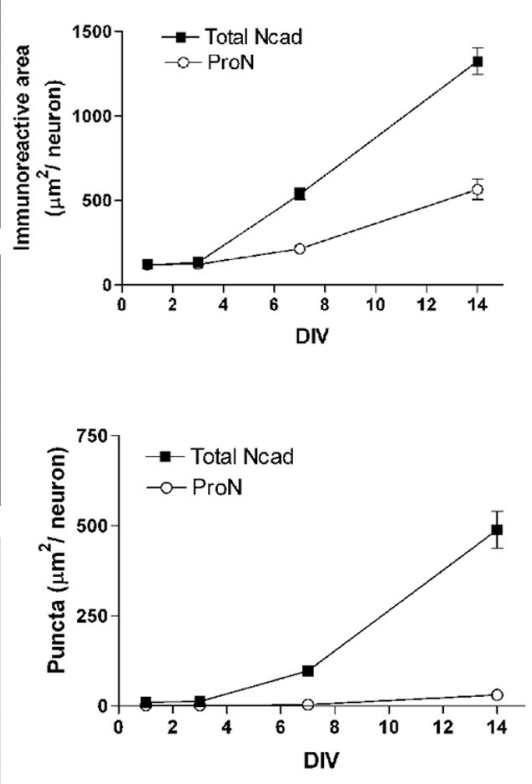

Figure 2. ProN versus total N-cadherin expression in hippocampal neurons. A, Primary hippocampal neurons stained for ProN (green) or total N-cad (red). At early stages of neuronal differentiation (3 DIV), ProN is highly expressed and the total N-cad pool consists mainly of ProN (quantified in the right panel). After $7 \mathrm{DIV}$, the relative contribution of ProN to the total N-cad pool drops considerably with simultaneous elevation in mature N-cad shown with a punctate distribution. B, ProN and total N-cad distribution shown at higher magnification. ProN distributes diffusely forming small puncta at 3 DIV. After 7 DIV, a high proportion of total N-cad distributes as larger puncta that fail to match with ProN labeling, demonstrating an increase in mature synaptic N-cad. C, ProN and N-cad distribution in detergent-soluble and -insoluble fractions. During differentiation, ProN and mature $\mathrm{N}$-cad distribute from the detergent-soluble to the detergent-insoluble fraction. ProN is predominantly expressed in the detergent-soluble fraction at the early stages of neuronal differentiation (3-7 DIV), while mature N-cad mainly distributes into the detergent-insoluble fraction during synaptogenesis (7 DIV onward). From 7 DIV onward, both ProN and N-cad distribute into the detergent-insoluble fraction. Densitometry reveals that the ProN/N-cad ratio drops significantly only in the soluble fraction during neuronal differentiation. The ProN/ $\mathrm{N}$-cad ratio drops to $\sim 1$ from 7 DIV onward, and constant levels are maintained that show no change in the detergent-soluble or -insoluble fractions. For comparison, expression levels and the distribution in the soluble and insoluble fractions of the synaptic proteins GluR1 and PSD-95 are also shown. The results are expressed as mean values \pm SD ( $n=4$ independent cultures). Scale bars: $A, 10 \mu \mathrm{m} ; \boldsymbol{B}, 0.5 \mu \mathrm{m}$. ${ }^{*} p<0.001$, compared with 7 DIV for the ProN/N-cad ratio in the soluble fraction or 3 DIV for ProN levels, by one-way ANOVA followed by Student-Newman-Keuls test. 
A
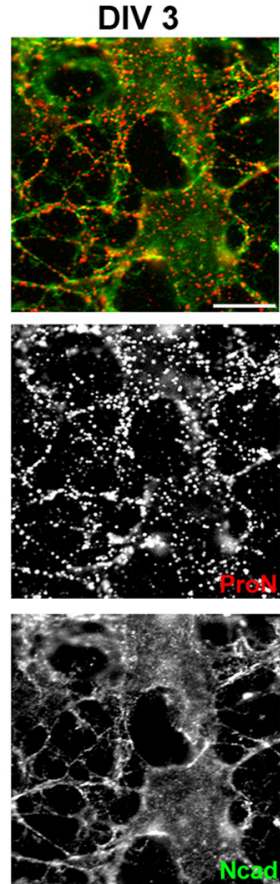

B

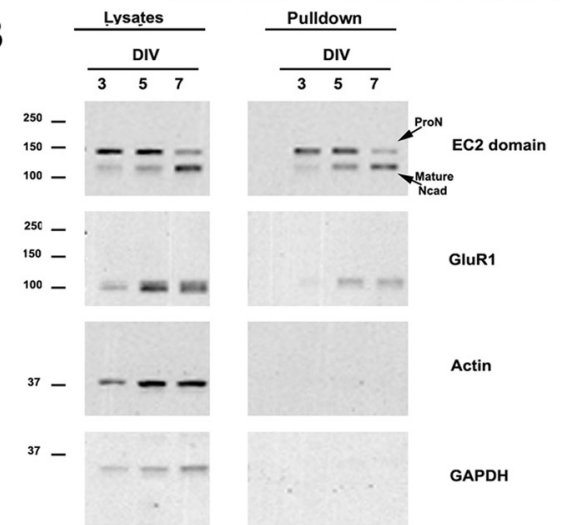

C

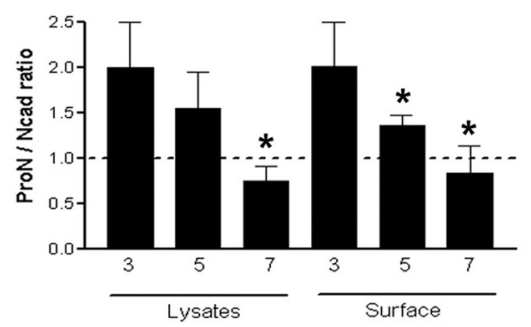

$\mathbf{E}$

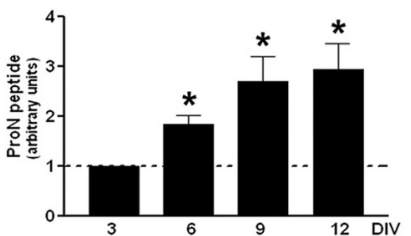

Figure 3. ProN is actively sorted to the cell surface during differentiation. $A$, Live hippocampal neurons ( 3 and 7 DIV) after staining with ProN antibody (red) were fixed and additionally stained for total Ncad (green). Note that the surface ProN levels diminish by 7 DIV and that ProN overexpression (cotransfection ProN/GFP, 4:1) leads to robust surface ProN expression. Scale bar, $10 \mu \mathrm{m}$. B, Biochemical evidence for surface sorting of ProN. Cell surface biotinylation supports the live staining data that ProN is actively sorted to the cell surface. The levels of surface (pulldowns) ProN drop significantly by 7 DIV, while the levels of mature N-cad increase markedly, coinciding with the elevation in the level of glutamate receptor (GluR1) at the cell surface. Actin and GADPH immunoblots show that the cytoplasmic proteins are spared from biotinylation. C, Quantification of ProN and N-cad levels in the total lysates and at the cell surface. The surface ProN/N-cad ratio drops significantly during differentiation. Results are expressed as mean values $\pm S D$ ( $n=3$ independent cultures). $\boldsymbol{D}, \boldsymbol{E}$, Release of processed prodomain by neurons. The ProN peptide accumulates in the culture media during neuronal differentiation. RP denotes the recombinant prodomain of ProN. The absence of bands when the immunoblot is incubated with ProN antibody that has been preincubation with RP demonstrates that the processed product in $\boldsymbol{D}$ is the prodomain of $\mathrm{N}$-cad. Results are expressed as mean values $\pm S D$ ( $n=3$ independent cultures). ${ }^{*} p<0.001$, compared with 3 DIV, by one-way ANOVA followed by Student-Newman-Keuls test.

Microscopy and analysis. All fixed cells were imaged using a $63 \times, 1.4$ numerical aperture oil-immersion objective on a Zeiss LSM 510 confocal microscope with an electronic zoom of 1 or 4 . Single optical sections and compression series (projections) of $z$-axis optical sections were used.
Data obtained from two channels simultaneously using a dichroic beam splitter were compared with data obtained sequentially using one laser line to ensure that emission spectra were clearly separated. Laser intensity and detector gain and offset were adjusted to avoid saturation and kept constant throughout. Measurements of immunolabeled puncta number and area were obtained from projections of $z$-axis optical sections series using NIH ImageJ program in which the threshold intensity was adjusted to maximize numbers of puncta and minimize the extent of fusion between puncta. Fluorescent puncta from a 50 $\mu \mathrm{m}$ region were measured in four to five dendrites per neuron ( $n=30$ neurons). Dendritic segments of similar thickness and location from the cell soma (normally the largest processes) were included for quantification. Spine morphology was analyzed in a $5 \mu \mathrm{m}$ region of four to five dendrites per neuron $(n=30$ neurons). The number of filopodia-like spines versus total number of spines per segment was counted. Thresholds were adjusted slightly between sections to maximize numbers of puncta and minimize the extent of fusion between puncta, but the threshold values did not differ within or across conditions. For quantitative analysis, four independent experiments were used in which 20-30 neurons were analyzed per condition. Statistical differences among conditions were evaluated by two-way ANOVA followed by Student-Newman-Keuls test (statistical significance was set at $p<0.05$ ).

Electrophysiology. Whole-cell patch-clamp recordings were performed on cultured hippocampal neurons (14 DIV). Voltage clamp was performed at a holding potential of -70 $\mathrm{mV}$. Currents were recorded at room temperature using an Axopatch 200B amplifier, digitized with a Digidata 3200A interface (Molecular Devices), and acquired at a frequency of $10 \mathrm{kHz}$ using pClamp 9. Recording electrodes were pulled from borosilicate glass tubes using a P-97 puller (Sutter Instrument) and fire-polished with a MP-830 microforge (Narishige) to a tip resistance of 3-6 M $\Omega$. Pipettes were filled with internal solution, containing the following (in $\mathrm{mM}$ ): $120 \mathrm{~K}$-gluconate, $20 \mathrm{KCl}, 2 \mathrm{MgCl}_{2}, 0.2$ EGTA, 10 HEPES, 7 di-tris phosphocreatine, 4 $\mathrm{Na}_{2}$ ATP, 0.3 Tris-GTP. $\mathrm{pH}$ was adjusted to 7.3 with $\mathrm{KOH}$. The perfusion solution, $\mathrm{pH} 7.4$, contained the following (in mM): $140 \mathrm{NaCl}, 5 \mathrm{KCl}, 2$ $\mathrm{MgCl}_{2}, 2 \mathrm{CaCl}_{2}, 10 \mathrm{HEPES}$, and $10 \mathrm{D}$-glucose. TTX $(0.3 \mu \mathrm{M})$ and picrotoxin $(0.05 \mu \mathrm{M})$ were added to block $\mathrm{Na}^{+}$channels and $\mathrm{GABA}_{\mathrm{A}}$ receptors, respectively. EPSC events were detected using the Mini Analysis software (Synaptosoft) and verified visually. Data are presented as mean \pm SEM, and analysis was performed using Student's $t$ test.

Electron microscopy. Rats were anesthetized and perfused transcardially ( $4 \%$ paraformaldehyde, $2 \%$ glutaraldehyde), and brains were removed and postfixed. Hippocampal sections were treated with $2 \% \mathrm{OsO}_{4}$ for $2 \mathrm{~h}$ and stained en bloc with uranyl acetate, dehydrated, and embedded in Epon. Ultrathin sections were cut and stained with uranyl acetatelead citrate and viewed in an electron microscope at 8300-50,000X 
A
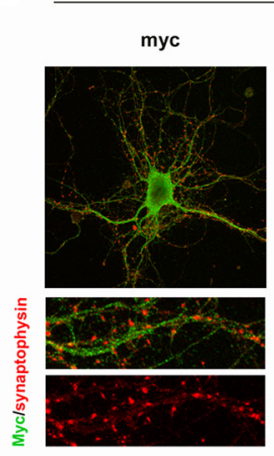

它点

\section{B}
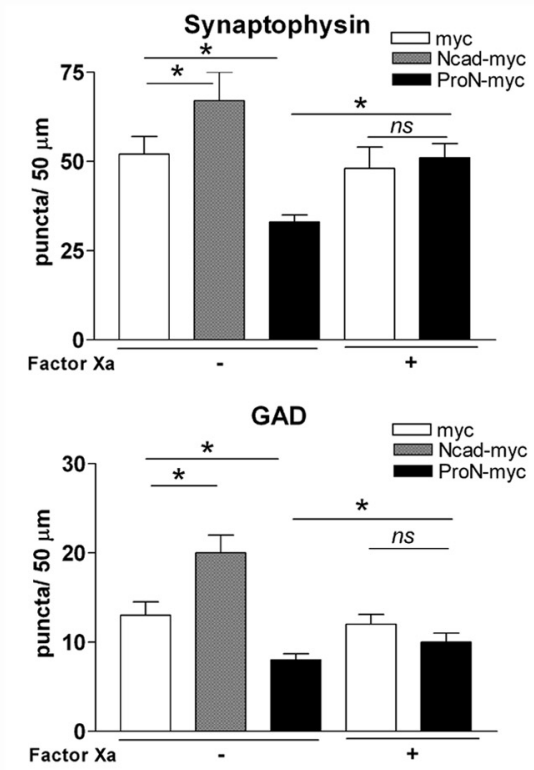

NO TREATMENT
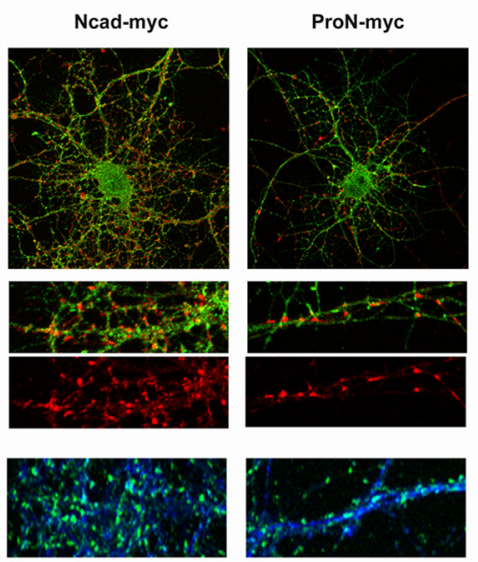

FACTOR Xa TREATMENT
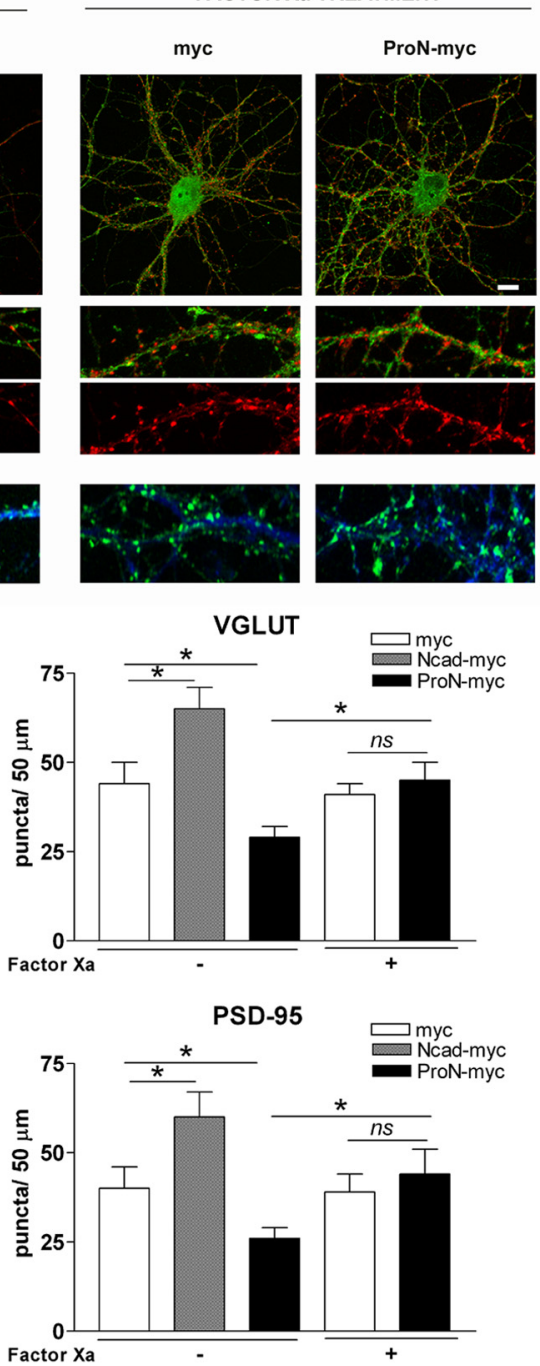

Figure 4. ProN expression inhibits synapse formation. Primary hippocampal neurons were transfected before plating with plasmids encoding a myc epitope (as control), wild-type N-cad (N-cad-myc), or uncleavable mutant ProN encoding a factor Xa cleavable site (ProN-myc). $\boldsymbol{A}$, The presynaptic and postsynaptic assembly in transfected hippocampal neurons was assessed at 14 DIV by synaptophysin and vGLUT1/2 (glutamatergic presynaptic marker) immunostaining. The bottom panels were costained for $\beta$ III-tubulin (blue). $\boldsymbol{B}$, Quantification of synaptic markers in transfected neurons. Neurons expressing uncleavable mutant ProN make markedly fewer synapses as revealed by significantly fewer synaptophysin, GAD, VGLUT1/2, and PSD-95 puncta. Synapse number can be rescued to normality by cleaving the prodomain by exogenous protease (factor Xa). Importantly, neurons expressing N-cad make significantly more synapses when compared with the control neurons (control vector; myc). Results are expressed as the mean number of puncta ( \pm SD) per $50 \mu \mathrm{m}$ of dendritic length from 30 neurons ( $n=30$ ). Scale bar, $10 \mu \mathrm{m}$. ${ }^{*} p<0.001$ between bars, by one-way ANOVA followed by Student-Newman-Keuls test.

magnification. Immunogold labeling was performed as described previously (Phend et al., 1995). In each immuno-electron microscopic (immuno-EM) section, gold grains localized to cell soma and plasma membrane were counted. Depending on their subcellular distribution, gold particles were divided into four main classes: (1) synaptic, (2) flanking a synapse, (3) nonsynaptic, and (4) soma restricted.

\section{Results}

ProN expression during hippocampal neuron differentiation and synaptogenesis

To determine the relative contribution of ProN during the process of neuritogenesis and synaptogenesis, we used a ProNspecific antibody (Koch et al., 2004) together with an antibody that recognizes both ProN and N-cad. ProN is localized to neuronal cell soma, dendrites, growth cones, and axons, and is in close relationship with the synapse in mature hippocampal neurons (Fig. $1 A-D$ ). ProN is detectable as early as $5 \mathrm{~h}$ after plating, and high levels of ProN persist until 5 DIV (Figs. $1 C, D, 2 A)$.

During the first $5 \mathrm{DIV}$, the total N-cad pool mainly consists of ProN (Fig. 2). During this early stage, the ProN staining is diffuse and small puncta are seen (Fig. $2 A, B$ ). From 5 DIV onward, the rate of ProN proteolytic processing increases, reducing ProN levels in the total N-cad pool (Fig. 2A-C). Note that, over time (7-14 DIV), an increasing proportion of total $\mathrm{N}$-cad concentrates as larger puncta that correspond to N-cad (Fig. 2A,B) and ProN concentrates in smaller puncta surrounded by a larger $\mathrm{N}$-cad disk. Several groups have reported N-cad expression in cultured neurons (Benson and Tanaka, 1998); however, our data for the first time demonstrate that, during early steps of neuritogenesis and synaptogenesis, it is ProN that predominates over $\mathrm{N}$-cad. Thus, the $\mathrm{N}$-cad expression analyzed during early steps in previous studies predominantly represents ProN and not the mature N-cad. 
A
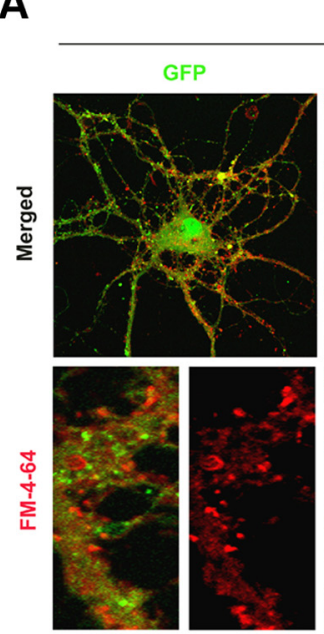

NO TREATMENT Ncad-GFP

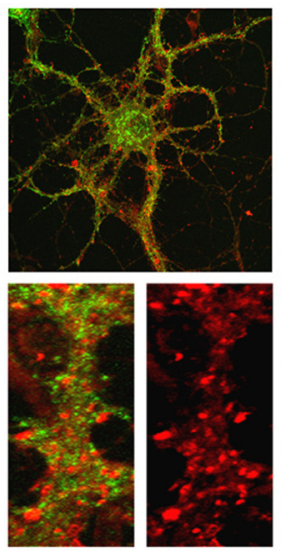

NO TREATMENT

B
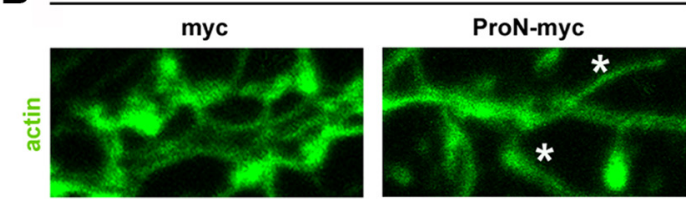

C

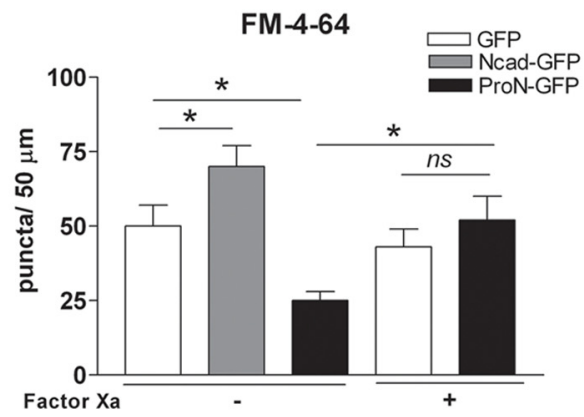

ProN-GFP

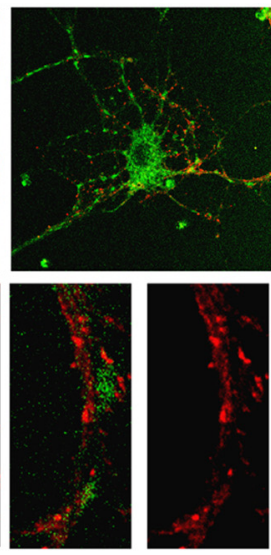

FACTOR Xa TREATMENT

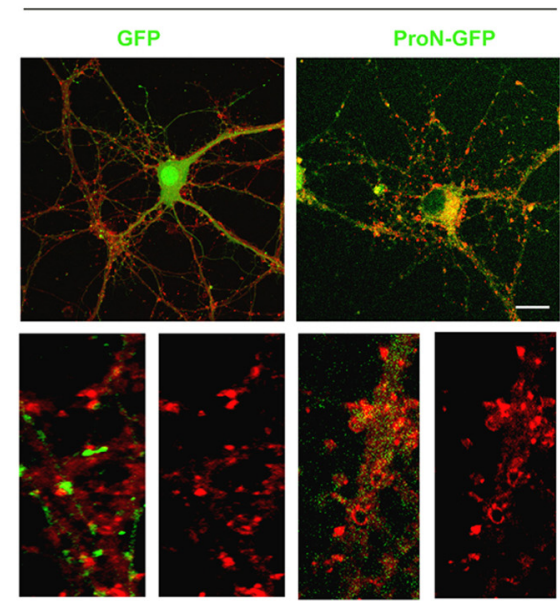

FACTOR Xa TREATMENT

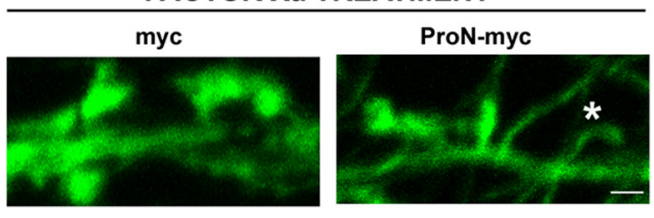

D

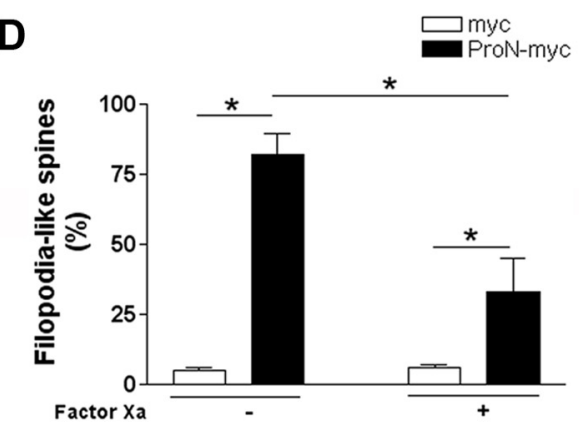

Figure 5. ProN expression reduces the number of synapses. Primary hippocampal neurons were transfected before plating with plasmids encoding GFP or myc (as control vector), wild-type N-cad (N-cad-GFP or N-cad-myc), or uncleavable mutant ProN (ProN-GFP or ProN-myc) protein. A, Labeling of presynaptic boutons with FM4-64 dye (14 DIV) shows a reduced number of active terminals in the ProN-transfected neurons. B, Dendrites of neurons expressing the mutant ProN show extremely long filopodia-like spines typical of immature synapses. $\boldsymbol{C}$, Quantification of FM4-64-labeled puncta shows that the synapse number can be partially rescued by cleaving the prodomain of the mutant ProN-GFP by supplementation with factor Xa. Results are expressed as the mean number of puncta ( \pm SD) per $50 \mu \mathrm{m}$ of dendritic length from 30 neurons $(n=30)$. $D$, Quantification shows that the ProN mutant conferred an immature phenotype and that factor Xa treatment partially restored spine morphology. Results are expressed as the percentage of filopodia-like spines ( \pm SD) in 30 neurons ( $n=3$ independent experiments). Scale bars: $\boldsymbol{A}, 10 \mu \mathrm{m} ; \boldsymbol{B}, 0.5 \mu \mathrm{m}$. ${ }^{*} p<0.001$ between bars, by one-way ANOVA followed by Student-Newman-Keuls test.

\section{Subcellular redistribution of ProN during synaptogenesis} We have previously reported that $\mathrm{N}$-cad partitions within a detergent-insoluble fraction (Tanaka et al., 2000). Here, we examined whether or not ProN is sorted to similar compartments. Quite surprisingly, during the early stages of hippocampal neuronal differentiation (1-5 DIV), ProN is present in the detergentsoluble fraction (Fig. 2C). From 7 DIV onward, ProN is reduced abruptly in the detergent-soluble fraction and significantly partitions into the detergent-insoluble fraction (Fig. 2C). N-cad, as previously reported, mainly partitions in the detergent-insoluble fraction after 7 DIV; however, significant levels are also found in the soluble fraction (Fig. 2 C). Interestingly, the ProN/N-cad ratio in the detergent-soluble fraction is high initially and shows a drastic reduction around the peak of synaptogenesis (7 DIV) and is maintained at $\sim 1$ in both the detergent-soluble and -insoluble fractions (Fig. 2C). ProN is nonadhesive and has been shown to be processed in the post-Golgi compartment by furin and other proteases; however, we find very high levels of ProN in proximity to both presynaptic and postsynaptic markers. Therefore, it is possible that the ProN staining that we observe is in the ER beneath the presynaptic and postsynaptic plasma membrane rather than at the synaptic plasma membrane. To investigate whether the ProN is at the cell surface or within the cell (in the ER), we stained live cells and, in addition, quantified the surface ProN with biotinylation assays (Fig. 3). We biotinylated the cell surface-expressed proteins with a membrane-impermeable analog of biotin and probed for ProN in the biotinylated pool. As deduced by the colabeling experiments (Figs. 1, 2), the biotinylation and surface staining experiments provide evidence for cell surface expression of ProN from 3 to 7 DIV (Fig. 3A-C). Precisely, in the cell lysate, the ProN/N-cad ratio drops from 2 at DIV 3 to 0.7 by DIV 7, and the surface ProN/N-cad ratio drops from 2 to 0.8 (Fig. 3C). This is coupled with a gradual increase in cleaved ProN peptide in the culture media of hippocampal neurons (Fig. $3 D, E$ ). Interestingly, the surface ProN/N-cad ratio drops suddenly during differentiation (Fig. $3 A-C$ ). At 7 
A
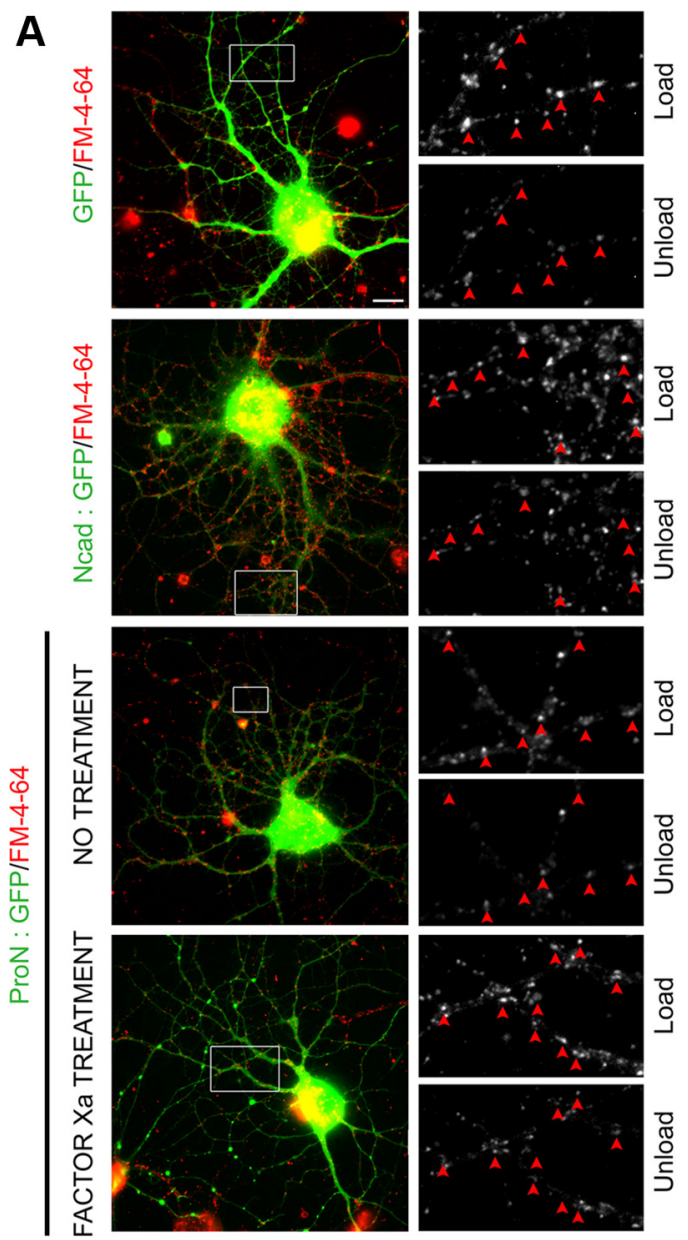

B

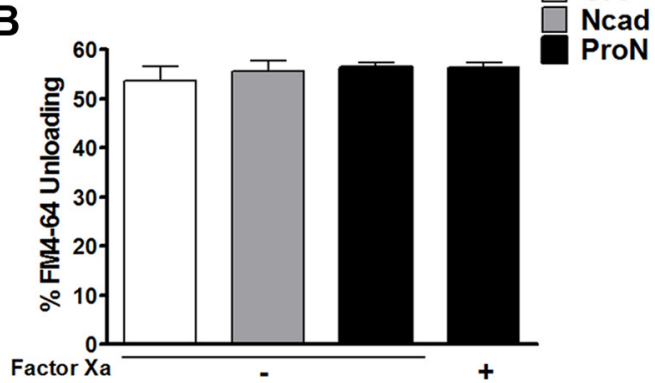

Figure 6. FM4-64-labeled functional synapses. Primary hippocampal neurons were transfected, as above, with EGFP (as control vector), N-cad (N-cad/GFP; 4:1), or ProN (ProN/GFP; 4:1). $A$, Representative overlays (left panel) showing live transfected neurons (green) labeled with FM4-64 dye (red). Scale bar, $10 \mu \mathrm{m}$. The boxed areas are magnified on right and show loading and unloading of active terminals. The arrowheads point to puncta showing a drop in fluorescence intensity. $\boldsymbol{B}$, The percentage of unloading in each group was similar. Quantifications from experiments ( $n=3$ ) on 6 (GFP), 13 (Ncad), 17 (ProN), and 13 (ProN factor Xa-treated) neurons show that the mean \pm SEM from four groups are not significantly different from each other (one-way ANOVA). The percentage unloading from $\geq 75$ puncta per neuron $(\sim 600-1300$ puncta per group) was calculated.

DIV, coinciding with the peak period of synaptogenesis in vitro, the availability of $\mathrm{N}$-cad shows sudden dramatic increase, suggesting that prodomain cleavage could play an important role during synaptogenesis.

The timing of ProN processing is a cell-intrinsic regulator of synaptogenesis

The progressive relative decrease in endogenous ProN and the parallel increase of $\mathrm{N}$-cad during synaptogenesis in cultured hip- pocampal neurons suggests that ProN might act as a cell-intrinsic negative regulator of synaptogenesis. The activity of ProN could be developmentally regulated by expression of an unknown cell surface-expressed protease that renders ProN inactive upon prodomain cleavage. To investigate whether absolute levels of ProN negatively regulate synapse formation in cultured neurons, we transfected hippocampal neurons with a mutant ProN expression construct (ProN mutant) in which the endogenous prodomain cleavage site was replaced by a factor Xa cleavage site, making it uncleavable by endogenous enzymes (Koch et al., 2004). Before analyzing the phenotype of ProN-expressing neurons, we investigated the effect of overexpression of wild-type $\mathrm{N}$-cad on synapse number. $\mathrm{N}$-cad overexpression increases the number of presynaptic endings when analyzed by synaptophysin labeling of the presynaptic puncta, whereas ProN mutant overexpression reduces the presynaptic ending number significantly $(p<0.001$, when compared with mock-transfected cells; Fig. $4 A, B)$. In addition to a reduction in the number of synaptophysin-positive puncta, expression of uncleavable ProN results in elongation of the remaining puncta (Fig. $4 A$ ), which previously has been described as a presynaptic organization defect (Togashi et al., 2002). Mutant ProN expression also results in reduction of the number of puncta corresponding to GABAergic and glutamatergic synapses, as shown by GAD and VGLUT $1 / 2$ immunostaining, respectively (Fig. $4 A, B$ ). When the ProN domain is cleaved by treating these neurons with exogenous factor $\mathrm{Xa}$, thereby favoring $\mathrm{N}$-cad expression, the synapse number is restored to control levels (Fig. 4A, B). In concordance with reduced presynaptic endings (evaluated with synaptophysin labeling), there is also a reduction in the number of postsynaptic endings in mutant ProN-expressing neurons (labeled with PSD-95; Fig. 4B). As expected, the cleavage of the prodomain by addition of factor Xa restores the postsynaptic puncta number to control levels (Fig. $4 A, B)$.

\section{ProN overexpression alters spine morphology and synaptic activity}

The labeling of presynaptic boutons with FM4-64 dye reaffirms the above observation that neurons expressing mutant ProN exhibit fewer functional synapses (Figs. $5 A, C, 6$ ), as seen by reduced number of FM4-64-labeled puncta. This drastic effect of mutant ProN expression is reversed when the prodomain sequence is cleaved by exogenous factor Xa treatment (Fig. $5 A, C$ ). The mock-transfected neurons show typical mushroom-like spine morphology. Mutant ProN expression results in extremely long filopodia-like spines typical of immature synapses (Fig. $5 B, D)$. This is associated with the formation of branches and the absence of synaptic specialization (Fig. 5B). Quantification confirms these observations and shows that the cleavage of the prodomain by addition of factor Xa partially restores spine morphology (Fig. 5B, $D$ ).

To determine whether factor Xa treatment of ProN-expressing neurons rescues synaptic activity, we performed wholecell voltage-clamp recordings on neurons (14 DIV) to measure the frequency of spontaneous EPSCs (sEPSCs) (Fig. 7). In neurons overexpressing $\mathrm{N}$-cad, the mean frequency of postsynaptic events was $2.98 \pm 0.61 \mathrm{~Hz}$. Expression of mutant ProN resulted in a dramatic reduction in the mean SEPSC frequency to $0.70 \pm$ $0.13 \mathrm{~Hz}$. The sEPSC frequency could be significantly rescued $(1.72 \pm 0.28 \mathrm{~Hz})$ by cleaving the prodomain with factor $\mathrm{Xa}$, demonstrating that the prodomain inhibits the spontaneous synaptic activity in cultured neurons (Fig. 7). 

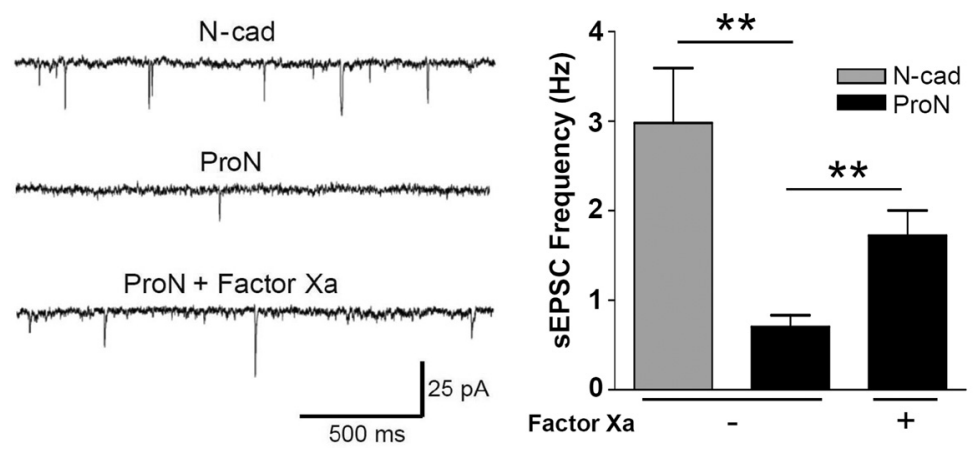

Figure 7. ProN expression reduces the spontaneous EPSC frequency. Representative traces (left) from whole-cell voltage-clamp recordings showing a higher frequency of sEPSCs in neurons transfected with N-cad (N-cad/GFP 4:1) compared with those transfected with ProN (ProN/GFP 4:1). Addition of factor Xa increases the frequency of spontaneous events in ProN-expressing neurons. Quantification of $\mathrm{sEPSC}$ frequency (right) shows a significant decrease in ProN-expressing neurons compared with $\mathrm{N}$-cad ${ }^{* *} p<$ $0.01 ; n=11)$. Factor Xa treatment rescues $s$ EPSC frequency in neurons transfected with mutant $\operatorname{ProN}\left({ }^{* *} p<0.01 ; n=9-11\right)$. Error bars indicate SEM.

\section{ProN expression and distribution is also regulated in the postnatal rat hippocampus}

We examined whether neurons in situ also exhibit a switch in ProN processing. In the rat CNS, at postnatal day 3 (P3), ProN localizes to the center of junctions formed by presynaptic and postsynaptic membranes (Fig. 8 A, C). By P15, ProN redistributes to flank the active zone after the critical period of synapse formation (Fig. $8 B, C$ ). These data demonstrate that ProN concentrates at synaptic sites during synaptogenesis in situ. We next examined the expression of $\mathrm{N}$-cad and ProN in the hippocampus during neuronal development (P1 to adult). As we have shown previously, $\mathrm{N}$-cad dimerization at the synaptic junction is resistant to Triton X-100, but not to SDS (Tanaka et al., 2000; Phillips et al., 2001). We therefore prepared Triton X-100-soluble and -insoluble hippocampal fractions. Similar to its distribution in cultured neurons (Fig. 2C), ProN predominantly partitions into the detergent-soluble fraction during the initial stages of neuronal differentiation (Fig. 8D), while it is expressed throughout all developmental stages in the soluble and insoluble fractions (Fig. $8 D, E)$. At $\mathrm{P} 1$, mature $\mathrm{N}$-cad levels are low, but there is a gradual increase between P3 and P5 (Fig. 8D-F), especially in the detergent-insoluble fraction (Fig. $8 E$ ). Comparison of the total ProN and $\mathrm{N}$-cad expression (soluble plus insoluble fractions) (Fig. $8 D, E$ ) reveals that quantitatively ProN predominates over $\mathrm{N}$-cad before P5 (Fig. $8 \mathrm{~F}$ ). Similar to the increased prodomain processing in cultured neurons (Fig. $2 C$ ), the ProN/N-cad ratio in rat hippocampus drops dramatically around P5-P7. At P10, there is a robust increase in $\mathrm{N}$-cad levels (Fig. $8 \mathrm{E}$ ). This period during development is coincident with the period of active synapse formation. Intriguingly, ProN is retained in the same insoluble fraction with $\mathrm{N}$-cad from developmental stage P10 to adulthood (Fig. 8 E). To examine whether or not ProN and $\mathrm{N}$-cad coexist at synaptic sites, we purified synaptic terminals from adult brain and isolated presynaptic and postsynaptic proteins. In agreement with previous reports (Beesley et al., 1995; Phillips et al., 2001), we also find $\mathrm{N}$-cad to be concentrated in the postsynaptic membranes. Surprisingly, we also find equal amounts of ProN in the postsynaptic membranes (Fig. $8 G$ ). These results imply that both adhesive and nonadhesive N-cad molecules coexist within synaptic sites in situ.

\section{Discussion}

We demonstrate that ProN and $\mathrm{N}$-cad are actively sorted to the surface of neurons generating a spectrum of adhesive strengths.
ProN processing and subcellular distribution is developmentally regulated and a high ProN/N-cad ratio at the cell surface initially sets up the nascent synapses. As this ratio drops, the presynaptic and postsynaptic membranes are locked. We propose that the developmental regulation of surface ProN processing regulates synaptogenesis.

Prodomain cleavage is considered as an obligatory final step for $\mathrm{N}$-cad maturation, so that no uncleaved N-cad (ProN) reaches the cell surface (Ozawa and Kemler, 1990; Posthaus et al., 1998; Wahl et al., 2003). We show sorting of high levels of ProN together with $\mathrm{N}$-cad to the surface of hippocampal neurons during maturation. These findings demonstrate that adhesive interactions mediated by $\mathrm{N}$-cad in maturing neurons are controlled by the interplay between the two $\mathrm{N}$-cad forms on the cell surface. Once at the surface, calcium-dependent homophilic interaction between $\mathrm{N}$-cad extracellular domains is required to generate a highly adhesive core between molecules from opposite plasma membranes (Boggon et al., 2002; Al-Amoudi et al., 2007). The structural model for cadherin adhesive function revealed that the presence of the prodomain completely changes the protein properties (Boggon et al., 2002; Koch et al., 2004). The prodomain sequence of $\mathrm{N}$-cad consists of an Ig-like domain and unstructured C-terminal region. The folded part of this sequence has a striking structural resemblance to the cadherin adhesive domains but lacks all the features known to be important for cadherincadherin interactions (Koch et al., 2004). Hence cells exhibiting perturbed levels of surface ProN show minimal adhesion (Koch et al., 2004; Latefi et al., 2009) and elevated migratory properties (Maret et al., 2010). In cultured neurons, we find high levels of ProN during the process of active neurite outgrowth. One plausible reason for this could be that neurite outgrowth requires the movement of membranes past each other, and therefore strong adhesive bonding would not be desirable during a period of rapid neurite outgrowth.

In mature neurons, $\mathrm{N}$-cad is mostly present in detergentinsoluble membrane microdomains (Tanaka et al., 2000) and is known to interact with catenins (Arikkath, 2009) and mediate clustering of glutamate receptors (Nuriya and Huganir, 2006; Saglietti et al., 2007). We show that, in contrast to N-cad, ProN is mostly found in the detergent-soluble fraction at early stages with dramatic redistribution into the insoluble pool after synaptogenesis. It is likely that, before synaptogenesis, the distribution of ProN over dendritic and axonal compartments in the detergentsoluble pool plays a role in inhibiting adhesion mediated by $\mathrm{N}$-cad. Interestingly, even during development, in situ ProN levels and distribution in the detergent-soluble pool are regulated, suggesting that ProN redistribution and processing are crucial steps that are regulated and coupled with synaptogenesis, in situ.

Processing of ProN into N-cad involves a posttranslational process that has been shown to occur in the late Golgi by an unknown furin protease (Ozawa and Kemler, 1990; Posthaus et al., 1998, 2003). Since the expression of furin proteases was shown to be developmentally regulated in different tissues (Kayo et al., 1996, 1997; Konda et al., 1997; Nakayama, 1997), the increased activity of such enzyme(s) could regulate the ratio of ProN/N-cad during development. Another possible regulatory mechanism could be increased 
internalization (Wu et al., 2008) as we also show that, as the CNS develops, ProN is found associated with plasma membrane tubular invaginations (Immuno EM; Fig. 8) previously described as related to endocytic phenomena (Smith et al., 2008; Dittman and Ryan, 2009). In addition, membrane-bound or extracellular enzymes are also likely mediators of cleavage, especially when taking into account that furin proteases are known to cycle from the Golgi to the cell surface (Molloy et al., 1994). Interestingly, in addition to intracellular proteolytic cleavage by $\gamma$-secretase (Uemura et al., 2006, 2007, 2009) or calpain (Jang et al., 2009), extracellular matrix proteasemediated cleavage of $\mathrm{N}$-cad has been recently reported (Reiss et al., 2005; Monea et al., 2006). Therefore, enzymes similar to the ones involved in the activation of prometalloproteases ( $\mathrm{Ra}$ and Parks, 2007) or metalloproteases are appealing candidates.

Since $\mathrm{N}$-cad is among the first adhesive molecules to accumulate at synaptic junctions (Togashi et al., 2002; Jontes et al., 2004), it has been proposed to initiate adhesive forces across the synaptic cleft. In fact, evidence indicating that disruption of $\mathrm{N}$-cad function inhibits synapse formation (Togashi et al., 2002; Bozdagi et al., 2004) and impairs axon targeting and cortical layering (Poskanzer et al., 2003; Kadowaki et al., 2007) supports the notion that $\mathrm{N}$-cad-mediated adhesion is a critical factor of synaptogenesis. The perturbed targeting of axons in null mice is likely due to lack of ProN function, and a high embryonic ProN expression may inhibit neurite adhesion, hence facilitating axonal pathfinding. This, however, is speculative, and transgenic mice overexpressing uncleavable ProN may provide insights into the in vivo role of high ProN levels during development.

$\mathrm{N}$-cad and its intracellular partners (catenins) are able to shape and adapt synaptic structure during synaptogenesis (Yu and Malenka, 2004; Junghans et al., 2005; Arikkath and Reichardt, 2008). Interestingly, the ProN/N-cad ratio decreases on the neuronal surface in such a way that the active period of synapse formation coincides with the highest availability of $\mathrm{N}$-cad. Conversely, the period before synaptogenesis is accompanied by high expression of ProN at the neuronal surface. Importantly, overexpression of uncleavable ProN inhibits synapse formation and alters presynaptic organization. The reduced labeling of active presynaptic boutons with FM4-64 dye and the reduction in sEPSC frequency validate these observations, revealing reduced synaptic activity in ProN-expressing neurons. Our results are in agreement with a previous report in which suppression of $\mathrm{N}$-cad function by overexpression of a dominant-negative mutant was
A

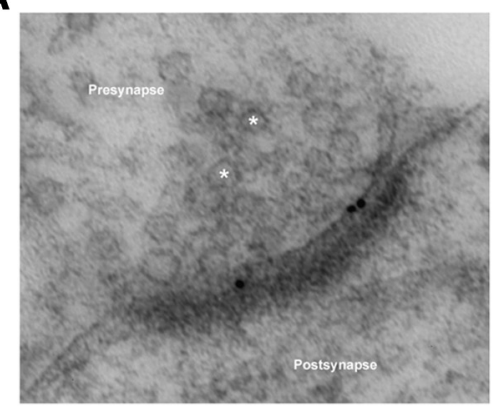

B

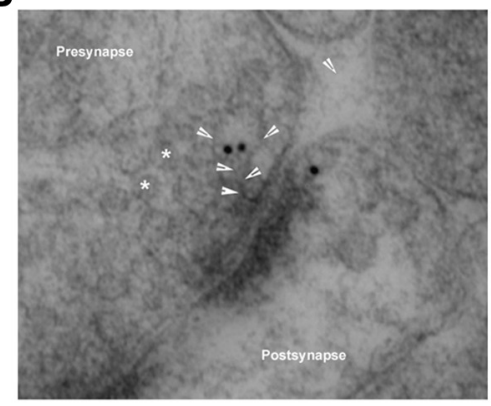

C
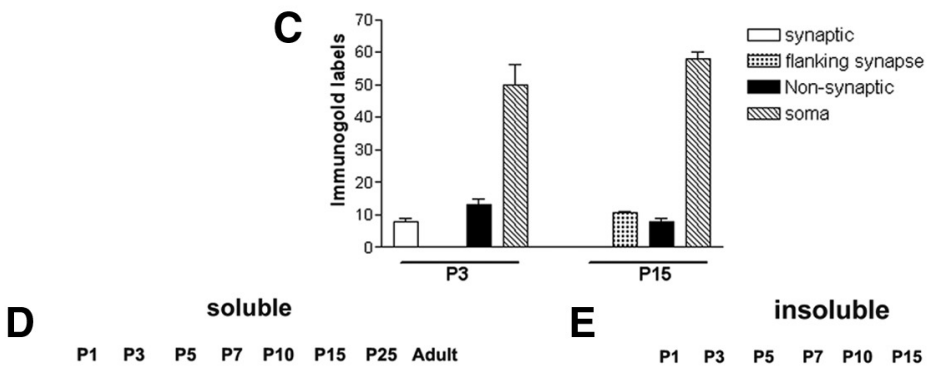

E

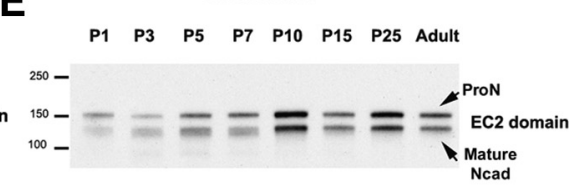

$F$

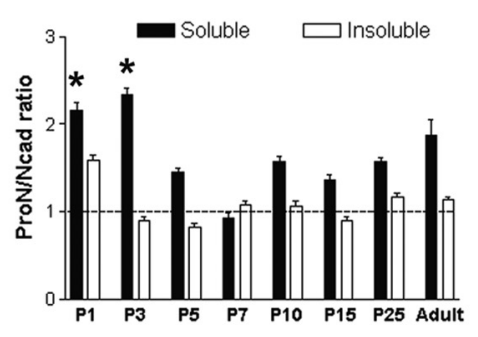

G

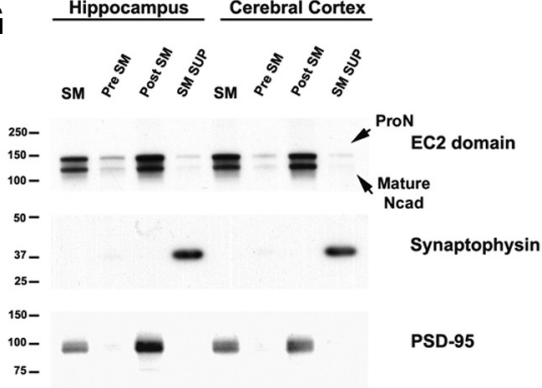

Figure 8. ProN is expressed at the synapse in situ. ProN synaptic localization was determined in the rat hippocampus by immuno-electron microscopy (immuno-EM) and synaptic fractionation. $\boldsymbol{A}, \boldsymbol{B}$, Immuno-EM labeling of ProN in the rat hippocampus at $\mathrm{P} 3$ reveals that ProN is present both at the presynapse and the postsynapse. By P15, ProN redistributes to the region flanking the active zone or is present in plasma membrane tubular invaginations. The asterisks indicate synaptic vesicles, and the arrowheads point at plasma membrane tubular invaginations. C, Quantification of the ProN immunogold labeling. Total gold grains in 10-15 immuno-EM sections obtained from two independent animals were counted and classified into the above-mentioned classes. At P3, the gold grains are seen at synaptic sites, at the plasma membrane, and at cell soma, but are absent from the zone flanking the active zone, also shown in $\boldsymbol{A}$. However, at P15, the synaptic gold grains are exclusively seen at the zone flanking the active zone, as shown in $\boldsymbol{B}$. There are no major differences in gold grains at the plasma membrane or soma between P3 and P15. D, E, Immunoblots show that ProN is present in both the detergent-soluble and -insoluble fractions during neuronal development and adulthood. Before P5, ProN is more abundant than mature N-cad. F, Quantification of the ProN/N-cad ratio in the detergent-soluble and -insoluble fractions. At early developmental stages, the ProN/N-cad ratio in the detergent-soluble fraction stays well above 1 , while the ratio in the insoluble fraction is tightly maintained at $\sim 1$. Results are expressed as mean values \pm SD $(n=2$ independent developmental series). G, Immunoblotting shows that ProN and mature N-cadherin are found in purified synaptic membranes (SM), and although present at the presynaptic side (Pre SM), the two forms are very concentrated at the postsynapse (Post SM). The PSD-95 and synaptophysin blots validate the purity of the postsynaptic and presynaptic fractions. ${ }^{*} p<0.001$, compared with P5, by one-way ANOVA followed by Student-Newman-Keuls test.

shown to impair presynaptic organization and synapse number (Togashi et al., 2002; Vitureira et al., 2012). Furthermore, Aiga et al. (2011) have recently shown that synapse density increases following N-cad overexpression (Aiga et al., 2011) only in young neurons. The discrepancy between our study and those that show no effect on synapse number after $\mathrm{N}$-cad overexpression (Okamura et al., 2004; Vitureira et al., 2012) could be attributed to the superior transfection rate $(>60 \%)$ in the current study, 
which was achieved by nucleofection before seeding the cells. Future studies focused on studying the effect of elevated N-cadmediated adhesion in the hippocampus of transgenic mice overexpressing wild-type and mutant $\mathrm{N}$-cad will shed more light on its role in regulating synapse number, in vivo. We also found that neurons overexpressing ProN exhibit spines with either filopodia-like structures or smaller elongated spine heads indicative of immature synapses (Harris, 1999; Abe et al., 2004; Takeichi and Abe, 2005). Dendritic spine defects manifested by the presence of thin elongated filopodia have been also observed when $\mathrm{N}$-cad or $\alpha \mathrm{N}$-catenin function is suppressed (Togashi et al., 2002; Abe et al., 2004). Together, we report a previously unrecognized critical step in the regulation of synaptogenesis involving the interplay of developmentally regulated ProN and N-cad at the neuronal surface, a mechanism interesting to be explored in conditions that affect synaptogenesis. We propose that, during CNS development, at the time during synaptogenesis when axon and dendrite outgrowth and branching are imperative for target recognition, predominance of ProN allows these processes. As the ProN versus N-cad balance progresses to favor adhesion, synapses begin to form, locking presynaptic and postsynaptic membranes to end in a synaptic configuration in which $\mathrm{N}$-cad confers the adhesive core flanked by a ProN reservoir. Hence, mature synapses involve ProN and $\mathrm{N}$-cad pools that differ in their size and synaptic distribution.

\section{References}

Abe K, Chisaka O, Van Roy F, Takeichi M (2004) Stability of dendritic spines and synaptic contacts is controlled by alpha N-catenin. Nat Neurosci 7:357-363.

Aiga M, Levinson JN, Bamji SX (2011) N-cadherin and neuroligins cooperate to regulate synapse formation in hippocampal cultures. J Biol Chem 286:851-858.

Al-Amoudi A, Díez DC, Betts MJ, Frangakis AS (2007) The molecular architecture of cadherins in native epidermal desmosomes. Nature 450:832-837.

Arikkath J (2009) Regulation of dendrite and spine morphogenesis and plasticity by catenins. Mol Neurobiol 40:46-54.

Arikkath J, Reichardt LF (2008) Cadherins and catenins at synapses: roles in synaptogenesis and synaptic plasticity. Trends Neurosci 31:487-494.

Beesley PW, Mummery R, Tibaldi J (1995) N-cadherin is a major glycoprotein component of isolated rat forebrain postsynaptic densities. J Neurochem 64:2288-2294.

Benson DL, Tanaka H (1998) N-cadherin redistribution during synaptogenesis in hippocampal neurons. J Neurosci 18:6892-6904.

Boggon TJ, Murray J, Chappuis-Flament S, Wong E, Gumbiner BM, Shapiro L (2002) C-cadherin ectodomain structure and implications for cell adhesion mechanisms. Science 296:1308-1313.

Bozdagi O, Shan W, Tanaka H, Benson DL, Huntley GW (2000) Increasing numbers of synaptic puncta during late-phase LTP: N-cadherin is synthesized, recruited to synaptic sites, and required for potentiation. Neuron 28:245-259.

Bozdagi O, Valcin M, Poskanzer K, Tanaka H, Benson DL (2004) Temporally distinct demands for classic cadherins in synapse formation and maturation. Mol Cell Neurosci 27:509-521.

Bozdagi O, Wang XB, Nikitczuk JS, Anderson TR, Bloss EB, Radice GL, Zhou Q, Benson DL, Huntley GW (2010) Persistence of coordinated longterm potentiation and dendritic spine enlargement at mature hippocampal CA1 synapses requires N-cadherin. J Neurosci 30:9984-9989.

Dhaunchak AS, Nave KA (2007) A common mechanism of PLP/DM20 misfolding causes cysteine-mediated endoplasmic reticulum retention in oligodendrocytes and Pelizaeus-Merzbacher disease. Proc Natl Acad Sci U S A 104:17813-17818.

Dhaunchak AS, Colman DR, Nave KA (2011) Misalignment of PLP/DM20 transmembrane domains determines protein misfolding in PelizaeusMerzbacher disease. J Neurosci 31:14961-14971.

Dittman J, Ryan TA (2009) Molecular circuitry of endocytosis at nerve terminals. Annu Rev Cell Dev Biol 25:133-160.

Fannon AM, Colman DR (1996) A model for central synaptic junctional complex formation based on the differential adhesive specificities of the cadherins. Neuron 17:423-434.

Harris KM (1999) Structure, development, and plasticity of dendritic spines. Curr Opin Neurobiol 9:343-348.

Jang YN, Jung YS, Lee SH, Moon CH, Kim CH, Baik EJ (2009) Calpainmediated $\mathrm{N}$-cadherin proteolytic processing in brain injury. J Neurosci 29:5974-5984.

Jontes JD, Emond MR, Smith SJ (2004) In vivo trafficking and targeting of $\mathrm{N}$-cadherin to nascent presynaptic terminals. J Neurosci 24:9027-9034.

Junghans D, Hack I, Frotscher M, Taylor V, Kemler R (2005) Beta-cateninmediated cell-adhesion is vital for embryonic forebrain development. Dev Dyn 233:528-539.

Jüngling K, Eulenburg V, Moore R, Kemler R, Lessmann V, Gottmann K (2006) N-cadherin transsynaptically regulates short-term plasticity at glutamatergic synapses in embryonic stem cell-derived neurons. J Neurosci 26:6968-6978.

Kadowaki M, Nakamura S, Machon O, Krauss S, Radice GL, Takeichi M (2007) N-cadherin mediates cortical organization in the mouse brain. Dev Biol 304:22-33.

Kayo T, Konda Y, Tanaka S, Takata K, Koizumi A, Takeuchi T (1996) Developmental expression of proprotein-processing endoprotease furin in rat pancreatic islets. Endocrinology 137:5126-5134.

Kayo T, Sawada Y, Suda M, Konda Y, Izumi T, Tanaka S, Shibata H, Takeuchi T (1997) Proprotein-processing endoprotease furin controls growth of pancreatic beta-cells. Diabetes 46:1296-1304.

Klein R (2001) Excitatory Eph receptors and adhesive ephrin ligands. Curr Opin Cell Biol 13:196-203.

Koch AW, Farooq A, Shan W, Zeng L, Colman DR, Zhou MM (2004) Structure of the neural $(\mathrm{N}-)$ cadherin prodomain reveals a cadherin extracellular domain-like fold without adhesive characteristics. Structure 12:793-805.

Konda Y, Yokota H, Kayo T, Horiuchi T, Sugiyama N, Tanaka S, Takata K, Takeuchi T (1997) Proprotein-processing endoprotease furin controls the growth and differentiation of gastric surface mucous cells. J Clin Invest 99:1842-1851.

Latefi NS, Pedraza L, Schohl A, Li Z, Ruthazer ES (2009) N-cadherin prodomain cleavage regulates synapse formation in vivo. Dev Neurobiol 69:518-529.

Lucido AL, Suarez Sanchez F, Thostrup P, Kwiatkowski AV, Leal-Ortiz S, Gopalakrishnan G, Liazoghli D, Belkaid W, Lennox RB, Grutter P, Garner CC, Colman DR (2009) Rapid assembly of functional presynaptic boutons triggered by adhesive contacts. J Neurosci 29:12449-12466.

Maret D, Gruzglin E, Sadr MS, Siu V, Shan W, Koch AW, Seidah NG, Del Maestro RF, Colman DR (2010) Surface expression of precursor $\mathrm{N}$-cadherin promotes tumor cell invasion. Neoplasia 12:1066-1080.

Mendez P, De Roo M, Poglia L, Klauser P, Muller D (2010) N-cadherin mediates plasticity-induced long-term spine stabilization. J Cell Biol 189:589-600.

Molloy SS, Thomas L, VanSlyke JK, Stenberg PE, Thomas G (1994) Intracellular trafficking and activation of the furin proprotein convertase: localization to the TGN and recycling from the cell surface. EMBO J 13:18-33.

Monea S, Jordan BA, Srivastava S, DeSouza S, Ziff EB (2006) Membrane localization of membrane type 5 matrix metalloproteinase by AMPA receptor binding protein and cleavage of cadherins. J Neurosci 26:2300-2312.

Nakayama K (1997) Furin: a mammalian subtilisin/Kex2p-like endoprotease involved in processing of a wide variety of precursor proteins. Biochem J 327:625-635.

Nuriya M, Huganir RL (2006) Regulation of AMPA receptor trafficking by N-cadherin. J Neurochem 97:652-661

Okamura K, Tanaka H, Yagita Y, Saeki Y, Taguchi A, Hiraoka Y, Zeng LH, Colman DR, Miki N (2004) Cadherin activity is required for activityinduced spine remodeling. J Cell Biol 167:961-972.

Ozawa M, Kemler R (1990) Correct proteolytic cleavage is required for the cell adhesive function of uvomorulin. J Cell Biol 111:1645-1650.

Phend KD, Rustioni A, Weinberg RJ (1995) An osmium-free method of Epon embedment that preserves both ultrastructure and antigenicity for post-embedding immunocytochemistry. J Histochem Cytochem 43:283-292.

Phillips GR, Huang JK, Wang Y, Tanaka H, Shapiro L, Zhang W, Shan WS, Arndt K, Frank M, Gordon RE, Gawinowicz MA, Zhao Y, Colman DR 
(2001) The presynaptic particle web: ultrastructure, composition, dissolution, and reconstitution. Neuron 32:63-77.

Poskanzer K, Needleman LA, Bozdagi O, Huntley GW (2003) N-cadherin regulates ingrowth and laminar targeting of thalamocortical axons. J Neurosci 23:2294-2305.

Posthaus H, Dubois CM, Laprise MH, Grondin F, Suter MM, Müller E (1998) Proprotein cleavage of E-cadherin by furin in baculovirus overexpression system: potential role of other convertases in mammalian cells. FEBS Lett 438:306-310.

Posthaus H, Dubois CM, Müller E (2003) Novel insights into cadherin processing by subtilisin-like convertases. FEBS Lett 536:203-208.

Ra HJ, Parks WC (2007) Control of matrix metalloproteinase catalytic activity. Matrix Biol 26:587-596.

Reiss K, Maretzky T, Ludwig A, Tousseyn T, de Strooper B, Hartmann D, Saftig P (2005) ADAM10 cleavage of N-cadherin and regulation of cellcell adhesion and beta-catenin nuclear signalling. EMBO J 24:742-752.

Saglietti L, Dequidt C, Kamieniarz K, Rousset MC, Valnegri P, Thoumine O, Beretta F, Fagni L, Choquet D, Sala C, Sheng M, Passafaro M (2007) Extracellular interactions between GluR2 and N-cadherin in spine regulation. Neuron 54:461-477.

Sakisaka T, Takai Y (2005) Cell adhesion molecules in the CNS. J Cell Sci 118:5407-5410.

Scheiffele P (2003) Cell-cell signaling during synapse formation in the CNS. Annu Rev Neurosci 26:485-508.

Shan W, Yagita Y, Wang Z, Koch A, Fex Svenningsen A, Gruzglin E, Pedraza L, Colman DR (2004) The minimal essential unit for cadherin-mediated intercellular adhesion comprises extracellular domains 1 and 2. J Biol Chem 279:55914-55923.

Shapiro L, Love J, Colman DR (2007) Adhesion molecules in the nervous system: structural insights into function and diversity. Annu Rev Neurosci 30:451-474.

Siddiqui TJ, Craig AM (2011) Synaptic organizing complexes. Curr Opin Neurobiol 21:132-143.

Smith SM, Renden R, von Gersdorff H (2008) Synaptic vesicle endocytosis: fast and slow modes of membrane retrieval. Trends Neurosci 31:559-568.

Tai CY, Mysore SP, Chiu C, Schuman EM (2007) Activity-regulated N-cadherin endocytosis. Neuron 54:771-785.
Takeichi M (2007) The cadherin superfamily in neuronal connections and interactions. Nat Rev Neurosci 8:11-20.

Takeichi M, Abe K (2005) Synaptic contact dynamics controlled by cadherin and catenins. Trends Cell Biol 15:216-221.

Tanaka H, Shan W, Phillips GR, Arndt K, Bozdagi O, Shapiro L, Huntley GW, Benson DL, Colman DR (2000) Molecular modification of N-cadherin in response to synaptic activity. Neuron 25:93-107.

Togashi H, Abe K, Mizoguchi A, Takaoka K, Chisaka O, Takeichi M (2002) Cadherin regulates dendritic spine morphogenesis. Neuron 35:77-89.

Uchida N, Honjo Y, Johnson KR, Wheelock MJ, Takeichi M (1996) The catenin/cadherin adhesion system is localized in synaptic junctions bordering transmitter release zones. J Cell Biol 135:767-779.

Uemura K, Kihara T, Kuzuya A, Okawa K, Nishimoto T, Bito H, Ninomiya H, Sugimoto H, Kinoshita A, Shimohama S (2006) Activity-dependent regulation of beta-catenin via epsilon-cleavage of $\mathrm{N}$-cadherin. Biochem Biophys Res Commun 345:951-958.

Uemura K, Kuzuya A, Aoyagi N, Ando K, Shimozono Y, Ninomiya H, Shimohama S, Kinoshita A (2007) Amyloid beta inhibits ectodomain shedding of N-cadherin via down-regulation of cell-surface NMDA receptor. Neuroscience 145:5-10.

Uemura K, Lill CM, Banks M, Asada M, Aoyagi N, Ando K, Kubota M, Kihara T, Nishimoto T, Sugimoto H, Takahashi R, Hyman BT, Shimohama S, Berezovska O, Kinoshita A (2009) N-cadherin-based adhesion enhances Abeta release and decreases Abeta42/40 ratio. J Neurochem 108:350-360.

Vitureira N, Letellier M, White IJ, Goda Y (2012) Differential control of presynaptic efficacy by postsynaptic $\mathrm{N}$-cadherin and beta-catenin. Nat Neurosci 15:81-89.

Wahl JK 3rd, Kim YJ, Cullen JM, Johnson KR, Wheelock MJ (2003) $\mathrm{N}$-cadherin-catenin complexes form prior to cleavage of the proregion and transport to the plasma membrane. J Biol Chem 278:17269_ 17276.

Wu JC, Yan HC, Chen WT, Chen WH, Wang CJ, Chi YC, Kao WY (2008) JNK signaling pathway is required for bFGF-mediated surface cadherin downregulation on HUVEC. Exp Cell Res 314:421-429.

Yu X, Malenka RC (2004) Multiple functions for the cadherin/catenin complex during neuronal development. Neuropharmacology 47:779786 